\title{
Political Role of Social Media as a Field of Research and as a Field of University Level Study
}

\author{
Dmitry Baluev \\ Nizhniy Novgorod State University Nizhniy Novgorod, Russia \\ dbalu@yandex.ru
}

\begin{abstract}
This article is drawing out major approaches to the study of political role of social media. On the one hand, in a nearest future such researches could be one of the main hot topics of political analysis. On the other hand, this field of study is starting to be reflected in leading universities' curriculum. However, common theoretical base for this field of study is still absent. An attempt to clarify terminology, picture out major approaches to the role of social media in politics, formulate major trends in this sphere of public life is made in this paper. It touches upon also consequences of rising political role of social media for foreign and security policy formulation. Possible applied use of this concept is a special interest for the author.
\end{abstract}

Keywords: Political role of social media, social networks, monitoring and measurement of social networks' activity

\section{Introduction}

Analysis of the current state of the problem: Since the start of rapid spread of Web-technologies in the early 1990s, the number of Internet users has grown from a few million to several billion. The society has gained access to a wealth of information and possibility to express opinion and take collective action independently of governments. At the same period, social media have become an integral part of civil society all over the world. Such media attract growing attention on the part of the corporate sector (Amerland, 2012). A significant landmark: in 2011, the most corporations increased their expenses for social media. The third part of major corporations heads have declared that social media has been at the top of their priority ranking (Booz \& Company, 2011). All this leads to rapid changes in media structure. Media audience has been changing as well as distribution over traditional and non-traditional media. There are a growing percentage of people acquiring information only from new media. Internet has become a political tool. Web is increasingly being used not only as an information platform, but as a coordinator of various mass actions. Moreover it has become a tool of military conflicts.

On one level, social media have become a tool for political movements' coordination around the world (Mattoni, 2012). On other level, regimes e.g. trying to withstand the U.S. influence, are seeking to limit access to social media. In response, the U.S. State Department has announced that the defense of "Internet freedom" is among its political priorities. Protection of the right of free use of Internet is needed to achieve U.S. strategic goal of the civil society strengthening throughout the world (the so-called "instrumental" approach). However, the U.S. State Department attempts to protect "Internet freedom" through support of various dissident groups outside the United States, aiming to replace the existing regimes, are generally not very effective, and, in the case of failure, the negative consequences can be severe. A more promising approach is social media perception as a long-term tool strengthening the civil society and the public sphere. In contrast to the "instrumental" approach, this one is called an "environmental" approach. In accordance with this concept, positive changes in the life of a country, including democratic regime change, are resulting from the civil society development. However, one may make out case against the idea that social media fundamentally influence changes in political life. First, the tools in their own, in the absence of formed public demand for political changes are ineffective. Second, they bring as much harm as good because authoritarian regimes are beginning to use these tools on their turn to deal with dissidents.

Such criticism is in some measure justified. Nevertheless, the question of social media influence is still open. Impossibility to make the world a better place with "one-click" does not mean the society or the state impossibility to effective use of social media to achieve socially significant goals. The recent events related to people protest activity in different countries have shown that the new media use does not 
supersede real actions, but rather serves as an effective tool for actions coordination. This does not mean that any political movement using these tools is doomed to succeed, because governments have not lost the ability to respond to such "threats". New technologies and changes in political systems reposture interaction between media and governments. If in the 1990s, it seemed that the development was going in the direction of unlimited freedom of information, despite the existing state borders, the beginning of the 21st century has shown that the world is not a place where information dissemination is free of all restrictions. Leading countries have managed to adapt to new technological and political realities, and media market changes. Moreover, new trends have led to great opportunities for some states to influence media in other countries. The way of media markets development in certain countries is no longer determined only by governments and their bureaucracies. Local media systems evolution has become a part of global media market.

Presently it is possible to identify six key trends affecting social media place in public life and in the field of education:

- Increase of competition and commercialization levels of the media market.

- Technical and economic convergence of traditional and "new" media.

- Media market globalization.

- Explosive growth in volume of available content.

- Increased opportunities for interactive use of content by end users.

- Increase of "new media" influence.

Growth of social activity in the web leads to strengthening governmental control over this sphere through monitoring, restriction and adaptation the same tools to its own needs. Due to the fact that the primary objective of the government is to prevent "political synchronization" of anti-government information, the state is trying not to limit access to the network, but to minimize access to certain information.

To date the Western political science has created a number of works on communication technologies (in the broadest sense, not limited to social media) impact on society. One of the first works dealing with the shift from communication technologies (TV, radio, newspapers) to information and communicative technologies is Howard Rheingold's book "The Virtual Community". Although the work was published in 1993, Reinhold managed to define a fundamental change in communication process: "new media attract colonies of enthusiasts because it enables people to do things with each other in new ways, and to do altogether new kinds of things--just as telegraphs, telephones, and televisions did" (Rheingold, 1993). J. Nye worked on issues that need to be considered at analysis of ways of technology conceptualization by society, emphasizing on "social structures" in the form of media. "The new media are not essentially democratic or totalitarian. Such social structure may represent a combination of both" (Nye, 2008). Benkler in his work in 2006 analyzes the transition from industrial to information economics. In the course of this transition not only economic institutions are changing, but also political and cultural ones (Benkler, 2006). Perlmutter in his study of 2008 analyzed a growing interest to blogs and came to such conclusion that blogging is not as powerful means of political campaigning from the point of view of traditional politics. While bloggers offer their readers unique information, they do not have financial, moral, social and cultural levers to change a specific political behavior (Perlmutter, 2008). Other researchers, for example Clay Shirky (Shirky, 2008), examine the new media possibility to mobilize political support. He has a broader vision than Perlmutter. Blogging is not the only subject of his analysis but also other Internet opportunities, such as Wikipedia and Twitter, showing us how politically active groups coordinate their actions more effectively than the "old" media.

Altogether, analyzing the Western political science, it should be noted that at the present time the studies considering political role of social media, are almost exclusively limited to their role in political mobilization and protest movements on the one hand, and the impact of social media on democratic regimes - on the other hand. In Russia, the social media political role consideration is mainly reduced to fragmentary discussions in blogosphere and reposts of foreign newsroom agencies information distantly related to the topic. It should be noted that there is no consensus on the nature of social media in Russian political and communication science. There is no universally accepted definition of social media, new media, social networks, which often leads to these concepts confusion. As a result a mid-level theory would be of great demand, explaining the impact of new communication technologies on political field, introducing a classification of different phenomena that we can observe in this area over the last five years, giving tools for theoretical research in this area, and practices in development and management of scientific projects related to new communication technologies political role research. Our study begun in 2009 was in some extent targeted to create such scientific and analytical tools. This article reflects certain 
results already achieved. It outlines a framework for design and implementation of research projects related to study of political role of social media and social networks, indicates main approaches to educational technologies that can be used for teaching of relevant disciplines of political science profile.

\section{Methodology of study of social media political role}

Critical aspects of creation and practical use of tools for social media political role analysis are the choice of methodological basis for study and clarifying the terminology issues. Regarding the methodological basis it should be noted that the crucial point is understanding the nature of social networks as the basis for functioning of social media and new media. It is necessary also for implementation of educational and scientific projects in this new, not fully understood and constantly evolving environment. Social networks determine social and economic life. For example, they play a central role in dissemination of information about job vacancies. Social networks are critical for trade. They are the basis for mutual support in developing countries. They determine the way of infectious diseases dissemination. They influence on the products we buy, the languages we speak, the voting we make, on our choice to become a criminal or to work in law enforcement, on the kind of education we get, on our success as professionals. Innumerable ways of social networks influence on political sphere are making absolutely necessary to understand:

- How social networks influence behavior;

- Which network structures can potentially appear in the society?

It is important to understand not just how many social links have each network member. Different degrees of cohesion and centrality of social network nodes allow us understanding different aspects of network structure. The theory of social networks analysis serves as the methodological basis of our research. The social network, understood in the framework of this theory, is a set of nodes (or network members) linked with each other by relations one or more types (Scott, 2012). Understanding the links between people, groups, governmental and non- governmental actors can help the understanding of the impact they have on each other. Facebook and other similar systems, contrary to popular opinion (among a large part of Russian researchers as well), are not social networks, but systems (or instrumental platforms) for social networks support. The real networks may exist and all too often successfully operate out of Facebook or any other such a platform. It appears that such a broad and general understanding of social networks is much more applicable to modern Russian social practice than the simplistic reduction of social networks variety only to those operating within social networks support systems. Such an approach is much more fruitful fro applied political analysis. In particular, the social network analysis theory has been successfully applied and is still applying for terrorist networks analysis. Therefore, the relevant social networks (not necessarily functioning within social networks support systems) should be one of the areas of subject field for any study related to political role of social media. Social networks set the methodological framework of such a study.

Regarding terminological framework we should clarify the understanding of such phenomena as social media, "new media", social media activity monitoring and measuring, "user-generated content", "participatory journalism", Web 2.0., "personalized" communication and political mobilization through the social media. Political and communication sciences have not yet settled generally accepted definitions of these phenomena. There is no understanding to what each of them relates: software-hardware platforms or social interaction models, content production or consumption, absolutely new political interaction models or new tools of "traditional" political process. New media are electronic media, often more dynamic than traditional ones, usually allowing the audience to interact with information creators. Nevertheless, not all "new media" are social media. The most striking example of the new media is Huffington Post, it has some tools bringing it together with social media, yet it can hardly be considered as a textbook example of social media. Social media (including Facebook and Twitter) are created to connect people. As such, they are used to deliver information to a large number of users in real time. Proper analysis of specific networks represents sequential execution of three steps that should be a part of any scientific project to study social media:

- Step 1: the network boundaries determination.

- Step 2: defining links between the network nodes or its members.

- Key point: the network members have an impact on each other to influence each other's actions. It is therefore important to understand how they relate to each other.

- Key point: it is necessary to understand the network links strength and nature to understand how it works.

- This allows us identifying the social networks and unknown issues important for understanding. 
- It makes us possible to compare different networks, identify the intersection points and analyze comparative levels of networks cohesion.

- Step 3: monitoring and evaluation of key indicators.

The social networks activities monitoring and measurement require a holistic approach, i.e. the process should include all activities relevant to the subject field consideration, regardless of whether it occurs in Facebook Twitter, YouTube or other social network support system. It is also necessary to recognize that despite some data overlap monitoring and measurement processes are different. Although both use similar data, these data are analyzed and used differently. Monitoring starts with definition of a set of keywords relevant to the subject field under study. Thereafter, keywords are entered into the monitoring tool tracing through information exchange and organizing the data for use in further analysis. Ideally, monitoring allows responding to various important information flows in real time. In contrast, the measurement has a statistical character and is not performed in real time, but for a certain (sometimes relatively long) period of time. As well as monitoring, measurement starts with definition of a set of keywords. After the monitoring tool performs data capture and primary analysis, it should be determined the numerical indicators most important to determine the state of the subject field under study. Regardless the field specifics such indicators will include involvement (Facebook page pertinence to users and actions they are taking visiting it), influence (number of links and likes to Facebook - a good tool to influence measuring is Netvibes), clicks, volume (how often people search in search engines for information located on Facebook page - the most widely used tool for volume measuring is Google Analytics), visitors demographics (the most relevant tool is HootSuite), intensity (measurement of number a particular message reposts in Twitter or Facebook). A perfect tool to measure influence and intensification is Klout, created with use of innovative methods and algorithms for complex influence measurement. The fairly relevant tool to measure the intensity in Twitter is TweetReach.

The highly important issue is comprehension of social media specific features and their difference from traditional media. Traditional media created and maintained one-way communication between few professional information creators and a variety of non-professional users. This model was most common in the second half of the twentieth century and began changing in the 1980s, due to wide spread of photocopiers, home video cameras, electronic printing systems and more available access to the Internet. By the beginning of the 2000s, cost of computers and Internet access has dropped so much to allow individuals using the same tools as professional news makers. It this period, new forms of media appeared such as blogs and social networking support systems. At this time, distinctions between news producers and consumers were blurred out. A new term appears: "user-generated content". It means a material product, but not the means of its production. The term is popular in commercial media and is used to explain business plans to investors, but it still draws a clear separating line between professionals and non-professionals. Sometimes such separation makes sense. For example, in July 2010, only three of the twenty most-viewed videos on YouTube were shot by amateurs. Most videos were shot in a studio products or professional high-budget music videos. The other term, "participatory journalism", focuses on running commentaries and transition from one-way broadcasting from a reporter to an audience to a multilateral dialogue between actors. The "Web 2.0" term refers to a model allowing users creating with the latest software platforms their own information sources. This term in contrast to the "user generated content" refers not to the final product, but to the new media creation tools. The Web 2.0. Concept is paying enough attention to processes, products, audience and authors. Although the term was created to describe a particular type of network programming, it is widely spread among social scientists. We define the "personalized" communications as communications that are the part of an organization or a coalition of organizations that:

- Provide an opportunity of a personal-oriented participation in problems.

- Absence of common ideological platform.

As a result of all these changes, highly centralized media system connecting people not with each other but with large centralized public entities and the centers of power is replaced by horizontal information flows between people. But the most important fact is that the new information and communication technologies are beginning to change the political world itself. The so-called "New Media" have been taking an independent political role, becoming a tool of political changes and the technology that is increasingly used for such changes. It is necessary to focus on the actual "new media" influence on politics and their use by political analysts. Social media are not the place to disseminate information by traditional methods. Approaches including press releases, flyers and direct mail just do not work in this environment. In conventional approaches to information dissemination a message is sent to a potential 
consumer of information. In social media you should create conditions at which the consumer is interested in consumption and even searching for information. Such conditions are created by inclusion of strong links between network elements, which are both producers and consumers of information. These links are absolutely necessary to connect individual users in a social network. In this regard it should consider that the social structure transformation is largely driven by social and technological revolution that swept all spheres of public life. The social structure analysis is associated with the informational way of interaction characterized by emergence of new social and technological schemes on the basis of formal and informal rules and norms in subjects' activities. The result is the ability to design and predict new forms of social reality and relationships with the help of modern information and communication technologies.

Studies conducted by Pew Center `s Internet and American Life show that even people rarely spending time online regularly use Internet to search for news and information. New media, often defined as social media, are quite different from online versions of print media, primarily by their interactive and collaborationist nature. Above all, they are characterized by two-way communication system, as well as by virtually no-cost use compared to traditional media, which are quite expensive. The old media are highly dependent from advertising, while during electoral campaigns candidates can use new media, in particular Twitter and Facebook, virtually free. During the U.S. presidential electoral campaign in 2008, 14.5 hours of video relating to the presidential race, were placed on YouTube. The cost of posting that video was virtually free, whereas, if such advertising volume was placed on TV, the estimated cost of advertising company would have amounted to \$ 45 million. Therefore, by virtue of interactive nature and low cost candidates may gain their supporters and voters by the way inaccessible via old media. A political campaign conducted with the help of new media helps to find new supporters. However it is difficult to say exactly how the new media affect voting behavior, while various political groups more frequently and widely use the new media in their campaigns.

\section{Conclusion}

Consideration of the political role of social media allows formulating a number of conclusions. First, the political role of social media is the subject of multiple speculations. However, it is studied less than the transformative role of social media, for example, in business. Over the past few years, such studies were well funded in respect of social media use by terrorist networks and their application to change the regimes in the Middle East. Second, a number of existing studies still substitute the concept of "social media" by the concept "social networks", the two terms are generally used as synonyms, but it is methodologically unacceptable. Third, monitoring and measurement of social networks activities can be the basic methods for theoretical researches and application analysis of specific cases of social media impact on political processes. Regarding social networks operating within social media frameworks, there is a fairly well developed set of software tools, successfully used in media markets studies and useful for studies of specific political campaigns in social media. Fourth, monitoring and measurement cannot be the only methods of such studies. A wide range of political methods and applied political analysis techniques should also be used. Fifth, despite the high attractiveness and efficiency of technologies underlying the Web 2.0., we should not consider them on their own as social phenomena. They just help to raise the interaction and information exchange, taking place within the framework of social media, to a new level. And this, in turn, leads to a change in the social systems users' roles. That is, the Web 2.0. Influence on political processes, is yet indirect despite its high degree. That is why the approaches existing in communication science are insufficient to concern the political role of social media. The approaches developed within the framework of political science, the security studies and the international relations theory are more relevant.

Studies of the political role of social media also allows identifying a number of trends that may be areas of further studies and should be reflected in the curricula of relevant disciplines:

- Emergence of so-called trans-media or use of two or more types of media for coverage has become a widespread phenomenon in 2012-13. Twitter has been the driving force of mixing TV and social media. Other related trend which had a huge impact on information perception by TV audience was the popularity of smartphones and tablet devices. According to research by Yahoo about 86 percent of TV viewers use such devices while watching TV.

- After Google had created a system of rewarding of those who created the content demanded by search engines, the race began to establish a system for accounting and reward those who created the 
most influential content. The undisputed leader in this area is Klout which has de facto become the industry standard for impact measuring systems.

- Ideas, opinions, multimedia content, status updates - these tools make social media more and more powerful and often disruptive force. Traditional media only come to realize this, adding similar features to their information systems.

- On the one hand, search engine on social networks are developing. On the other hand, social media are increasingly influencing the search engines results. Pages shared by users in Facebook, Twitter or Google get higher ranks in users search results.

- Other trend is development of so-called social intelligence (similar to corporate intelligence). In 2011, the number of social media monitoring tools available in the market reached more than 200 and continues to grow.

- In the near future we should expect breakthroughs in creation of more accurate social networks influence measuring systems. Such breakthroughs can be expected in three systems: Klout, Kred and PeerIndex.

These trends will be crucial in the near future for development of experts' subject matter in the field of communications and political science. They will certainly contribute to the toolkit of relevant studies and development and management of research projects to study the social and political role of new media. This, in turn, would have an impact on the educational sphere. On the one hand, the object world is changing, where the educational system products act, employers' demands are also changing. On the other hand, new ways of scientific knowledge of this world appear and this should also be reflected in the learning process.

\section{References}

Amerland, D. (2012). The Social Media Mind: How social media is changing business, politics and science and helps create a new world order. New Line Publishing.

Benkler, Y. (2006). The Wealth of Networks: How Social Production Transforms Markets and Freedom. Yale University Press.

Booz \& Company and Buddy Media's. (2011). Campaigns and Capabilities: Social Media and Marketing.

Mattoni, A. (2012). Media Practices and Protest Politics. Ashgate.

Nye, J. S. (2008). The Powers to Lead. Oxford University Press, 2008.

Perlmutter, D. (2008). Blogwars. Oxford University Press.

Rheingold, H. (1993) The Virtual Community: Homesteading on the Electronic Frontier, (free in HTML form).

Scott, J. P. (2012). Social Network Analysis. Second Edition. SAGE Publications.

Shirky, C. (2008). Here Comes Everybody: The Power of Organizing Without Organizations. 